$1-1-2013$

\title{
Value-based analysis of routine pathologic septal and inferior turbinate specimens.
}

\author{
James J Daniero \\ Thomas Jefferson University \\ Jaemi S Chu \\ Thomas Jefferson University \\ Brian J O'Hara \\ Thomas Jefferson University \\ Edmund A. Pribitkin \\ Thomas Jefferson University
}

Follow this and additional works at: https://jdc.jefferson.edu/otofp

Part of the Otolaryngology Commons

Let us know how access to this document benefits you

\section{Recommended Citation}

Daniero, James J; Chu, Jaemi S; O'Hara, Brian J; and Pribitkin, Edmund A., "Value-based analysis of routine pathologic septal and inferior turbinate specimens." (2013). Department of Otolaryngology - Head and Neck Surgery Faculty Papers. Paper 22.

https://jdc.jefferson.edu/otofp/22

This Article is brought to you for free and open access by the Jefferson Digital Commons. The Jefferson Digital Commons is a service of Thomas Jefferson University's Center for Teaching and Learning (CTL). The Commons is a showcase for Jefferson books and journals, peer-reviewed scholarly publications, unique historical collections from the University archives, and teaching tools. The Jefferson Digital Commons allows researchers and interested readers anywhere in the world to learn about and keep up to date with Jefferson scholarship. This article has been accepted for inclusion in Department of Otolaryngology - Head and Neck Surgery Faculty Papers by an authorized administrator of the Jefferson Digital Commons. For more information, please contact: JeffersonDigitalCommons@jefferson.edu. 


\title{
As submitted to:
}

\section{Otolaryngology-head and neck surgery}

\author{
And later published as:
}

\section{Value-based Analysis of Routine Pathologic Septal and Inferior Turbinate Specimens}

\section{March, 2013, Volume 148, Issue, 3: pp: 509-12. doi: $10.1177 / 0194599812472656$. \\ Epub 2013 Jan 11}

Authors:

1st: James J. Daniero, M.D.

Department of Otolaryngology - Head \& Neck Surgery, Thomas Jefferson University, Philadelphia, PA

2nd: Jaemi S. Chu, B.S.

Department of Biochemistry and Molecular Biology, Ursinus College, Collegeville, PA

3rd: Brian J. O'Hara, M.D.

Department of Anatomic Pathology, Thomas Jefferson University, Philadelphia, PA

4th: Edmund A. Pribitkin, M.D.

Department of Otolaryngology - Head \& Neck Surgery, Thomas Jefferson University, Philadelphia, PA

Presentation at the American Academy of Otolaryngology- Head and Neck Surgery Foundation (AAO-HNSF) Annual Meeting, Washington, DC, September 10, 2012

Keywords: cost-effectiveness; septoplasty; turbinectomy; nasal surgery; pathology

Word count: 1412 


\author{
Corresponding Author: \\ James J. Daniero, MD \\ Thomas Jefferson University Hospital \\ Department of Otolaryngology - Head and Neck Surgery \\ 925 Chestnut St, 6th floor \\ Philadelphia, PA 19107 \\ phone: 215-298-3708 \\ facsimile: $215-923-4532$ \\ email: jdaniero@gmail.com \\ Financial Disclosures: None \\ Conflicts of Interest: None
}


Objective. To determine the frequency and clinical relevance of unanticipated histopathologic results in routine sinonasal surgery and evaluate the necessity for histologic processing of nasal septal cartilage, bone, and inferior turbinate specimens.

Study Design. Case series with chart review.

Setting. Tertiary care academic medical center.

Subjects and Methods. A retrospective review of surgical pathology reports on adult patients undergoing sinonasal surgery during a five-year period from 2005 to 2010 was performed. All cases with the preoperative diagnosis of sinonasal neoplasia, autoimmune disease, or directed septal biopsies were excluded from review.

Results. A total of 1194 pathology reports were reviewed from 1172 individual patients. This included histopathologic evaluation of 1194 septal cartilage and bone specimens and 714 inferior turbinate specimens. None of the patients had unanticipated histopathologic findings that were clinically significant.

Conclusions. Many surgeons obtain histopathologic diagnoses on all tissue removed from a patient. Based on our institutional case series, histopathology of the septum and inferior turbinates in routine sinonasal cases may not be necessary. A value-based approach to processing grossly unremarkable septal and turbinate tissue by waiving histologic processing and subsequent 
microscopic evaluation could provide significant cost savings.

\section{Introduction}

Septoplasty and turbinectomy may be performed as a separate procedure or in conjunction with other nasal surgery such as, endoscopic sinus surgery or rhinoplasty. In the absence of adenoid hypertrophy and nasal polyposis, septoplasty and turbinectomy have been shown to result in a significant improvement in nasal airflow and quality of life. ${ }^{1,2}$ According to the National Center for Health Statistics over 196,000 turbinectomies and 260,000 nasal septoplasties were performed in 2006 in the United States. ${ }^{3},{ }^{4}$ Routine microscopic examination of nearly all surgically removed tissue is a standard practice at many institutions to document removal and pathologically determine a diagnosis. However, given the relative infrequency of unexpected findings after routine histologic processing of septal cartilage and turbinate tissue, the costeffectiveness and clinical relevance of this practice warrants scrutiny.

A similar controversy exists regarding the histologic processing of adenotonsillectomy specimens in children. A 1996 survey of the American Society of Pediatric Otolaryngology members showed disagreement in routine handling of adenotonsillectomy specimens, with $56 \%$ reporting routine microscopic analysis, $42 \%$ reporting gross examination only, and $2 \%$ reporting that they discard routine specimens. ${ }^{5}$ Similarly, a 1999 survey of the American Academy of Otolaryngology members was performed to analyze the evolution of private practice patterns in handling adenotonsillectomy specimens. This survey 
revealed a decreasing trend from $65 \%$ to $38 \%$ of members electing microscopic analysis of routine pediatric adenotonsillectomy specimens over a ten year period from 1989 to $1999 .{ }^{6}$ Cost considerations and supporting literature were cited as the main reasons for changing pathology practices. However, to our knowledge no practice pattern study has been performed regarding the handling of nasal septum and inferior turbinate specimens.

The aim of this study is to review the results of histopathologic analysis of routine septal cartilage and turbinectomy specimens and to present a more cost-effective and value-based approach to handling these specimens. A literature review failed to identify any prior study analyzing the utility of routine septal cartilage and turbinate pathologic analysis.

\section{Methods}

Approval from the institutional review board of the Thomas Jefferson University and Hospitals was obtained to review the hospital records of patients undergoing nasal surgery during the years 2005 through 2010 . The patient records of four otolaryngologists who routinely perform nasal surgery and submit specimens for pathologic analysis were reviewed for inclusion in the study at the Thomas Jefferson University Hospital, a tertiary academic medical center. A retrospective chart review was performed of all patients with routine septal cartilage specimens. The operative and pathology reports were reviewed to identify the patient demographics, procedure, indication, and pathologic diagnosis. All cases 
with a preoperative diagnosis of sinonasal neoplasia, autoimmune disease, or directed septal biopsies were excluded. In this subset of patients, the pathologic diagnoses of any associated inferior turbinate specimens were also reviewed. Gross and histopathologic examination of almost all specimens was performed as per routine in our practice. Patients were not included in this study if the tissue specimens were discarded in the operating room and not processed through the pathology department. This resulted from the method of data collection by reviewing surgical pathology reports and were a minority of cases due to costconsiderations of self-pay patients. The technique resulting in removed septal tissue varied widely in accordance with varying surgical indications. However, the inferior turbinate specimens were all obtained by direct "cold steel" excision.

\section{Results}

A total of 1194 septal cartilage and 714 turbinate specimens were sent for pathologic analysis from 1172 individual patients, including 616 males and 568 females. The patient's ages ranged from 13 to 85 , with a mean age of 40 . The indications for the procedures included nasal obstruction, chronic rhinosinusitis, cosmetic nasal deformity, and septal perforation. The procedures performed included septoplasty with or without turbinectomy, internal nasal valve repair, rhinoplasty, endoscopic sinus surgery with septoplasty and turbinectomy, and septal perforation repair. The number of excluded directed biopsies that yielded neoplasm could not be determined based on the data collected due to the method of collection automatically excluding these patients from analysis. 
No occult malignancies were identified in any of the 1,908 routine specimens, but $62(3.2 \%)$ specimens had an unanticipated incidental pathologic diagnosis that did not affect patient care. Four of the specimens were processed for gross examination only; all were limited to septal specimens. The majority of the microscopic analyses of the specimens revealed a diagnosis of chronic inflammation within cartilage and bone with associated inflammatory changes in overlying mucosa. Nineteen of the septal cartilage specimens and forty-two of the inferior turbinate specimens resulted in a diagnosis other than benign tissue or expected chronic inflammatory changes. Incidental pathologic diagnoses included squamous metaplasia, polypoid tissue, necrotic tissue, foreign body reaction (from previous surgery), necrotizing venulitis, fibropurulent exudate, ulceration, papilloma, hyperkeratosis/parakeratosis, and fungal hyphae. Table 1 shows the distribution of the incidental diagnoses in the nasal septum and inferior turbinate specimens. One specimen that was suspicious for squamous papilloma was an isolated finding and did not have associated features of inverted papilloma or progress to recurrent papilloma. There was a notable increased incidence of squamous metaplasia in the turbinectomy specimens with 33 of 714 (4.6\%) specimens compared to 3 of $1194(0.3 \%)$ septal specimens. However, given the non-specific nature of this diagnosis related to chronic inflammation, this difference is not likely to be clinically relevant. Charts of the unsuspected diagnoses were reviewed for subsequent development a clinically significant sinonasal disease. There was no subsequent change in diagnosis based on 
post-surgical follow-up averaging 16 months (ranging from 2 weeks to 5 years). One patient with necrotizing venulitis of the septum underwent an autoimmune work-up to determine the source of the vasculitis. The testing was negative and the patient did not develop any further clinical symptoms in 16 months of followup. Four patients with the diagnosis of hyperkeratosis or parakeratosis did not show any evidence of neoplastic growth during follow-up. It is worth noting that one patient excluded due to the preoperative suspicion of carcinoma, demonstrated initial septal biopsies with only squamous metaplasia after two separate procedures, however subsequent speciments resulted in the diagnosis of adenosquamous carcinoma a year later.

\section{Discussion}

In our current health care environment, cost containment is an increasingly important priority. Health care reform efforts continue to move towards a valuebased health care delivery system, with an emphasis on efficient production of good outcomes. ${ }^{7,8}$ Accordingly, the American Academy of Otolaryngology- Head and Neck Surgery has joined the American Board of Internal Medicine Foundation and several other specialties in promoting the "Choosing Wisely" campaign. As part of "Choosing Wisely," each society has developed a list of 5 commonly used tests, treatments, or services which should be reevaluated. ${ }^{9}$ Although nasal surgery specimens may not be a "top five" priority, this cultural shift in patient care encourages a critical assessment of current standard practices. 
There have not been previous studies examining the cost effectiveness of pathologic examination of nasal surgery specimens; however, several studies addressing tonsillectomy and adenoidectomy specimens were identified. ${ }^{5,10,11}$ Nelson et al. reviewed 15 adenotonsillectomy studies including a total of 19,045 pediatric patients, of which only 4 patients had unsuspected clinically relevant diagnoses (3 unsuspected lymphomas, 1 glycogen storage disorder). The group further demonstrated an estimated cost per case of unsuspected clinically relevant pathology of $\$ 584,000 .{ }^{10}$ Similarly, a retrospective review of 868 endoscopic sinus surgeries resulted in 2 occult malignancies, a rate of 0.23 percent. $^{12}$

For the purposes of economic analysis in this study, Medicare reimbursement rates were used, because they more accurately reflect true economic costs when compared to hospital charges due to the wide variation in billing practices. The Medicare reimbursement for the CPT code $88304 \mathrm{TC}$ is $\$ 55.16$ covering the technical component for processing of a tissue specimen (i.e. the expense borne by the institution). The reimbursement for $88304 \mathrm{PC}$ is $\$ 11.45$ for the professional component covering the pathologist's interpretation. Therefore, a total cost of $\$ 66.71$ for each specimen sent to pathology for gross and histopathologic examination is accrued. For our institution at least $\$ 6,364$ per surgeon per year was spent on routine processing of sinonasal specimens. When amplified by the estimate of 260,000 septoplasties and 196,000 turbinectomy mentioned previously, $\$ 30.4 \mathrm{M}$ in cost savings could potentially be realized. ${ }^{13,14}$ 
or 0.3 percent. This upper limit implied that based on the observed data we conclude that the real event rate can be no more than about 1:333 patients. Since this is reasonably low, it further supports the hypothesis that testing is not necessary.

However, if there is a clinical suspicion for cancer, vasculitis, granulomatous diseases, and benign neoplasms, the surgeon must continue to actively pursue the diagnosis with adequate tissue for pathologic analysis. This was clearly demonstrated by the excluded patient that eventually was diagnosed with adenosquamous carcinoma of the nasal septum after multiple biopsies and a year of follow-up.

\section{Conclusion}

Many surgeons choose to obtain histopathologic evaluation on all tissue removed from a patient. However, the relative infrequency of unsuspected clinically relevant pathology found in this case series supports a decision to waive pathologic analysis of routine nasal septum and inferior turbinate specimens. In the current era of cost-containment in medicine, using a value-based approach to processing routine tissue by waiving histopathologic evaluation could provide significant cost savings. However, surgeons should continue to maintain vigilance and identify signs and symptoms suggestive of an underlying pathology and request appropriate histopathologic evaluation when indicated. 


\section{Acknowlegment}

The authors would like to thank Eric Ehiei, M.D. for assistance with data collection. 


\section{References:}

1. Kemker B, Liu X, Gungor A, Moinuddin R, Corey JP. Effect of nasal surgery on the nasal cavity as determined by acoustic rhinometry. Otolaryngol Head Neck Surg. 1999;121(5):567-571.

2. Stewart MG, Smith TL, Weaver EM, et al. Outcomes after nasal septoplasty: results from the Nasal Obstruction Septoplasty Effectiveness (NOSE) study. Otolaryngol Head Neck Surg. 2004;130(3):283-290.

3. Bhattacharyya N. Ambulatory sinus and nasal surgery in the United States: Demographics and perioperative outcomes. Laryngoscope. 2010;120(3):635638.

4. National Center for Health Statistics. National Health Statistics Reports Number 11 January 28, 2009-Revisied September 4, 2009. 2009:1-28.

5. Dohar JE, Bonilla JA. Processing of adenoid and tonsil specimens in children: a national survey of standard practices and a five-year review of the experience at the Children's Hospital of Pittsburgh. Otolaryngol Head Neck Surg. 1996;115(1):94-97.

6. Strong EB, Rubinstein B, Senders CW. Pathologic analysis of routine tonsillectomy and adenoidectomy specimens. Otolaryngol Head Neck Surg. 2001;125(5):473-477.

7. Berwick DM, Hackbarth AD. Eliminating waste in US health care. JAMA. 
2012;307(14):1513-1516.

8. Porter ME. A strategy for health care reform--toward a value-based system. $N$. Engl. J. Med. 2009;361(2):109-112.

9. Cassel CK, Guest JA. Choosing Wisely: Helping Physicians and Patients Make Smart Decisions About Their Care. JAMA. 2012.

10. Nelson ME, Gernon TJ, Taylor JC, McHugh JB, Thorne MC. Pathologic Evaluation of Routine Pediatric Tonsillectomy Specimens: Analysis of CostEffectiveness. Otolaryngol Head Neck Surg. 2011;144(5):778-783.

11. Younis RT, Hesse SV, Anand VK. Evaluation of the utility and costeffectiveness of obtaining histopathologic diagnosis on all routine tonsillectomy specimens. Laryngoscope. 2001;111(12):2166-2169.

12. Romashko AA, Stankiewicz JA. Routine histopathology in uncomplicated sinus surgery: is it necessary? Otolaryngol Head Neck Surg. 2005;132(3):407412.

13. Hall MJ, Lawrence L. Ambulatory surgery in the United States, 1996. Adv Data. 1998;(300):1-16.

14. Owings MF, Kozak LJ. Ambulatory and inpatient procedures in the United States, 1996. Vital Health Stat 13. 1998;(139):1-119. 
Table 1. Unsuspected pathologic diagnoses.

\begin{tabular}{|l|c|c|}
\hline & $\begin{array}{c}\text { Nasal } \\
\text { Septum }\end{array}$ & $\begin{array}{c}\text { Inferior } \\
\text { Turbinate }\end{array}$ \\
\hline $\begin{array}{l}\text { Squamous } \\
\text { metaplasia }\end{array}$ & 1194 & 714 \\
\hline Polypoid tissue & 3 & 33 \\
\hline Necrotic tissue & 3 & 1 \\
\hline $\begin{array}{l}\text { Foreign body } \\
\text { reaction }\end{array}$ & 1 & 0 \\
\hline Necrotizing venulitis & 1 & 0 \\
\hline $\begin{array}{l}\text { Fibropurulent } \\
\text { exudate }\end{array}$ & 1 & 0 \\
\hline Ulceration & 3 & 1 \\
\hline Papilloma & 1 & 0 \\
\hline $\begin{array}{l}\text { Hyperkeratosis/ } \\
\text { Hyperparakeratosis }\end{array}$ & 3 & 1 \\
\hline Fungal hyphae & 1 & 0 \\
\hline
\end{tabular}

